Cite this: J. Mater. Chem. C, 2013, 1, 850

Received 13th September 2012 Accepted 15th November 2012

DOI: $10.1039 / c 2 t c 00180 b$

www.rsc.org/MaterialsC

\title{
Electrospun UV-responsive supramolecular nanofibers from a cyclodextrin-azobenzene inclusion complex $†$
}

\begin{abstract}
Menglin Chen, ${ }^{\text {*a }}$ Søren Roesgaard Nielsen, ${ }^{a}$ Tamer Uyar, ${ }^{\mathrm{b}}$ Shuai Zhang, ${ }^{a}$ Ashar Zafar, ${ }^{\mathrm{c}}$ Mingdong Dong ${ }^{a}$ and Flemming Besenbacher ${ }^{a}$

A combination of the unique hosting properties of cyclodextrins (CDs) and the peculiar UV-responsive trans-cis isomerization of the guest molecule azobenzene has endowed light-responsibility of the inclusion complex (IC). The IC of 4-aminoazobenzene (AAB) and hydroxypropyl- $\beta$-cyclodextrin (HP $\beta C D)$, with its inherent viscosity from hydrogen bondings between $C D$ s and $\pi-\pi$ stacking between $A A B s$, was electrospun into nanofibers from water without using any carrier polymer matrix. The integrity of electrospun ICs was proven by thermogravimetric analysis (TGA), differential scanning calorimetry (DSC), together with Fourier transform infrared spectroscopy (FTIR) and X-ray diffraction (XRD). The homogeneous distribution of HPBCD-AAB-IC was confirmed by surface chemistry mapping using timeof-flight secondary ion mass spectrometry (ToF-SIMS). The UV response of ICs prior to, during and post electrospinning was investigated. UV irradiation prior to electrospinning caused precipitation of $A A B$ from the aqueous IC solution. UV irradiation during electrospinning flight demonstrated the interruption of ICS and consequently broader diameter distributions were obtained. Post-spinning UV irradiation induced topography and adhesion force changes on the electrospun nanofiber surfaces, demonstrated by in situ atomic force microspectroscopy (AFM) quantitative nanomechanical mapping. The present study is the first case where the supramolecule with stimuli response was electrospun into nanofibers with retained activity.
\end{abstract}

\section{Introduction}

Cyclodextrins (CDs) have been extensively studied for over half a century ${ }^{1}$ mainly because of their peculiar hosting properties. The truncated cone structure made of glucopyranose units has endowed CDs a unique combination of a hydrophilic outer surface, where the hydroxyl groups are located, and a hydrophobic inner cavity to host various hydrophobic molecules and form water-soluble inclusion complexes (ICs). These biocompatible, cyclic oligosaccharides do not elicit immune responses and have low toxicities in animals and humans. Therefore, CDs are used extensively to host various drugs in pharmaceutical applications for numerous purposes, including the improvement of bioavailability, efficacy, specificity, tolerability and therapeutic index of corresponding drugs. ${ }^{2}$

Upon oral and parenteral administration, drugs appear to be rapidly dissociated from CD ICs, where diffusion upon dilution

anterdisciplinary Nanoscience Center (iNANO), University of Aarhus, DK-800o, Denmark.E-mail:menglin@inano.au.dk

${ }^{b}$ UNAM-Institute of Materials Science \& Nanotechnology, Bilkent University, Ankara 06800, Turkey

'Department of Mechanical and Manufacturing Engineering, Aalborg University, Aalborg, DK-900o Denmark

† Electronic supplementary information (ESI) available: Experimental procedures and characterization are provided. See DOI: 10.1039/c2tc00180b appears to be the major release mechanism. ${ }^{3}$ While drugs ideally are released in a controlled manner from a formulation, the concept of controlling the release upon external stimulus is extremely desirable. ${ }^{4}$ A particularly intriguing possibility is offered by light-responsive materials allowing remote and accurate operation that can easily be focused into specific areas of applications. The photo-response of these materials is based on the photo-isomerization of constituent molecules that undergo a large conformational change between two states in response to the absorption of light at two different wavelengths. ${ }^{5}$ Typically, the trans-cis isomerization of azobenzene chromophores, ${ }^{6}$ which reversibly interconvert between an extended, thermally relaxed trans isomer and a higher energy cis or "bent" isomer, gives rise to changes in the dipole moments, polarity, or shape of the molecules. Thus, these azobenzene chromophores have opened up a large variety of utilizations in the synthesis of new intelligent nanomaterials. ${ }^{7}$ The geometry change associated with azobenzene photoisomerization $(\sim 0.7 \mathrm{~nm})$ has been used to control protein activity by light by attaching azobenzene to ligands. ${ }^{7 a}$ Azobenzenes have also been applied to ion channels in the nervous system to facilitate optical control of electrical activity in neurons. ${ }^{8}$

Light-responsive azobenzene has been found to be able to form inclusion complexes (ICs) with CDs in its trans state, ${ }^{9}$ while its cis form is too bulky. Such a supramolecular 


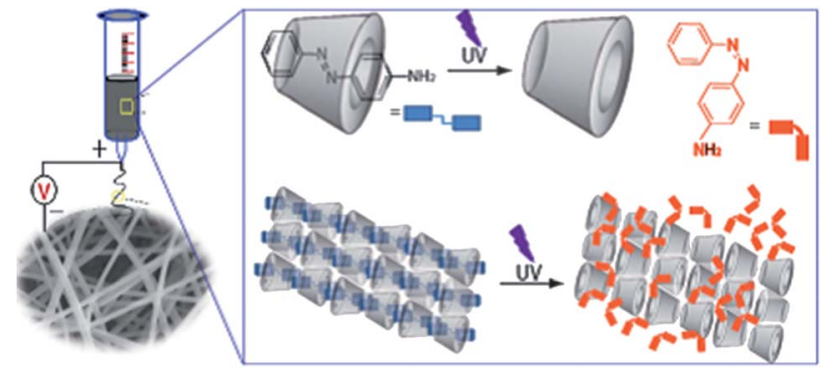

Scheme 1 Electrospinning of UV responsive HPBCD-AAB-ICs.

system has thus been further explored because of its light responsibility. ${ }^{\mathbf{1 0}}$

Electrospinning is a polymer processing technique that produces continuous nano- to microscale fibers through the action of an external electric field imposed on a rich variety of polymer melts or solutions that include synthetic or natural polymers, or composite polymer blends with small molecules. It is crucial to the presence of polymer chain entanglements in the charged fluid that ensures the fluid does not break up into droplets but forms a stable jet when the electrostatic repulsive forces on the fluid surface overcome the surface tension. ${ }^{\mathbf{1 1}}$ Nevertheless, supramolecular chemistry further pushes the technique beyond the limited choice of materials within polymers; instead small amphiphiles such as phospholipids ${ }^{\mathbf{1 2}}$ and gemini surfactants, ${ }^{\mathbf{1 3}}$ self-assembled diphenylalanine, ${ }^{\mathbf{1 4}}$ and supramolecular polymers from heteroditopic monomers ${ }^{15}$ have been successfully electrospun into fibers, since these molecules can form supramolecules and entangle in a fashion similar to polymers.

Unlike classical amphiphiles, CDs show a low polar character, indicated by their cohesion energy distribution, and have no dipolar or vectorial contribution but a quadrupolar character. ${ }^{16}$ The self-assembly of CDs had thus not been taken into account until the last decade, where some evidence of selfaggregation of CDs in solution was observed by different microscopies, especially at concentrated solutions. ${ }^{17}$ It is thus intriguingly interesting that recently the electrospinning of $\mathrm{CDs}^{18}$ and $\mathrm{CD}-\mathrm{ICs}^{19}$ has been accomplished without any polymer matrix. Furthermore, there is still very few known concerning the photo-response behavior of electrospun nanofibers based on CDs. ${ }^{20}$

Here we describe the first study of electrospun UV-responsive supramolecular nanofibers from ICs of hydroxypropyl- $\beta$-cyclodextrin (HPßCD) with 4-aminoazobenzene (AAB) (Scheme 1). ToF-SIMS was utilized for surface chemical mapping. Thermophysical properties of the electrospun ICs were studied by TGA and DSC, while the structural analyses were performed by FTIR and XRD. The UV response of ICs prior to, during and post electrospinning was investigated, applying AFM quantitative nanomechanical mapping.

\section{Results and discussions}

\section{Electrospinning of HPßCD-AAB-ICs}

Clear orange HPßCD-AAB-IC solutions were successfully prepared and electrospun without the addition of any carrier polymeric matrix. $\mathrm{CD}-\mathrm{AAB}$ ICs are known to be able to aggregate through hydrogen bondings between CDs and $\pi-\pi$ stacking between AABs. ${ }^{9}$ The representative SEM images of the electrospun HP $\beta \mathrm{CD}-\mathrm{AAB}-\mathrm{IC}$ nanofibers are displayed in Fig. 1. Beads of HP $\beta C D-A A B-I C$ (Mat I, $1: 0.3$ molar ratio, HP $\beta C D$ $100 \mathrm{w} / \mathrm{v} \%$ ) (Fig. 1a) were obtained with diameters in the range of $0.8-5 \mu \mathrm{m}$ due to the low entanglement of the assembled molecules. In the case of HP $\beta$ CD-AAB-IC (Mat II, $1: 0.9$ molar ratio, $\mathrm{HP} \beta C D 120 \mathrm{w} / \mathrm{v} \%$ ), the beads were stretched and connected by nanofibers with the fiber diameter range of 200$900 \mathrm{~nm}$ (Fig. 1b). HPßCD-AAB-IC (Mat III, 1 : 0.7 molar ratio, $\mathrm{HP} \beta \mathrm{CD} 140 \mathrm{w} / \mathrm{v} \%)$ resulted in nano-microfibers of diameters of $0.2-1.7 \mu \mathrm{m}$ with very few elongated beads (Fig. 1c). At higher concentrations, bead-free electrospun fibers (Fig. 1d) having the fiber diameter range of $0.6-1.5 \mu \mathrm{m}$ with an average fiber diameter of $1.08 \pm 0.29 \mu \mathrm{m}$ were obtained with HP $\beta C D-A A B-I C$ (Mat IV, 1:1 molar ratio, HPßCD $130 \mathrm{w} / \mathrm{v} \%$ ). Table 1 summarizes the morphology information together with their diameter distributions.
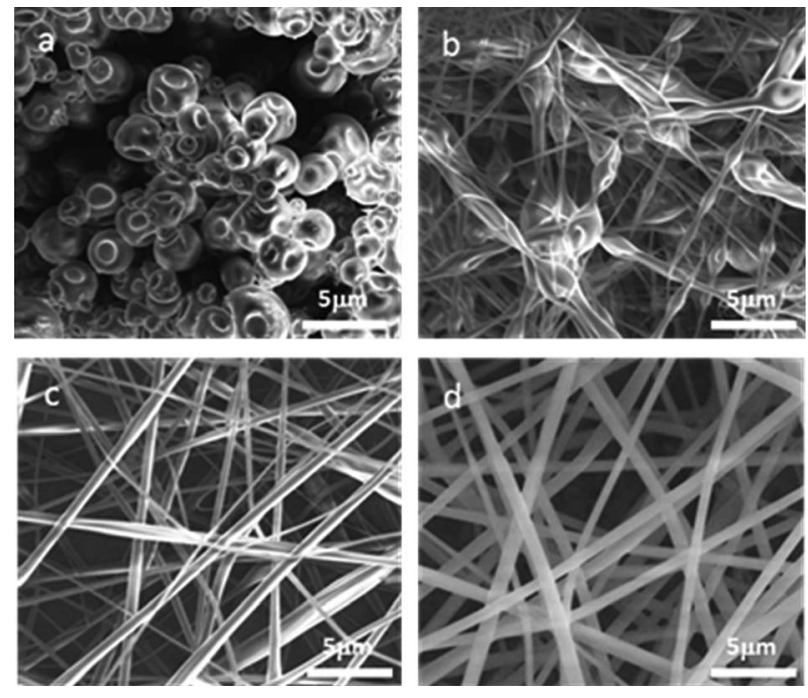

Fig. 1 SEM images of electrospun HPBCD-AAB-ICs.

Table 1 Electrospinning of HP $\beta C D-A A B-I C S$

\begin{tabular}{|c|c|c|c|c|c|}
\hline Mat & $\begin{array}{l}\% \\
\text { HP } \beta C D \\
(w / v)\end{array}$ & $\begin{array}{l}\% \\
\text { AAB } \\
(w / v)\end{array}$ & $\begin{array}{l}\text { HP } \beta C D-A A B \\
\text { molar ratio }\end{array}$ & Morphology & $\begin{array}{l}\text { Bead/fiber } \\
\text { diameter } \\
(\mathrm{nm})\end{array}$ \\
\hline I & 100 & 4 & $1: 0.3$ & Beads & $2.32 \pm 1.14 \mu \mathrm{m} /$ \\
\hline II & 120 & 12 & $1: 0.9$ & $\begin{array}{l}\text { Beaded } \\
\text { nanofibers }\end{array}$ & $\begin{array}{l}1.93 \pm 1.24 \mu \mathrm{m} / \\
0.46 \pm 0.17 \mu \mathrm{m}\end{array}$ \\
\hline III & 140 & 12 & $1: 0.7$ & $\begin{array}{l}\text { Nano- } \\
\text { microfibers } \\
\text { (with very } \\
\text { few elongated } \\
\text { beads) }\end{array}$ & $\begin{array}{l}-/ \\
0.94 \pm 0.23 \mu \mathrm{m}\end{array}$ \\
\hline IV & 130 & 16 & $1: 1$ & $\begin{array}{l}\text { Nano- } \\
\text { microfibers }\end{array}$ & $-/ 1.08 \pm 0.29 \mu \mathrm{m}$ \\
\hline
\end{tabular}




\section{ToF-SIMS spectra and chemical mapping}

ToF-SIMS was applied to identify the molecules and map their distribution on the surfaces of individual beads or fibers with a depth resolution of 1-2 $\mathrm{nm}$. The principal component analysis (PCA) clearly shows the intensive signals from HP $\beta C D$, such as $m / z 31\left(\mathrm{CH}_{3} \mathrm{O}^{+}\right), m / z 43\left(\mathrm{C}_{2} \mathrm{H}_{3} \mathrm{O}^{+}\right), m / z 57\left(\mathrm{C}_{3} \mathrm{H}_{5} \mathrm{O}^{+}\right), m / z 85$ $\left(\mathrm{C}_{4} \mathrm{H}_{5} \mathrm{O}_{2}{ }^{+}\right), m / z 127\left(\mathrm{C}_{6} \mathrm{H}_{7} \mathrm{O}_{3}{ }^{+}\right), m / z 143\left(\mathrm{C}_{7} \mathrm{H}_{11} \mathrm{O}_{3}{ }^{+}\right), m / z 203$ $\left(\mathrm{C}_{10} \mathrm{H}_{19} \mathrm{O}_{4}^{+}\right)$and $m / z 221\left(\mathrm{C}_{9} \mathrm{H}_{17} \mathrm{O}_{6}{ }^{+}\right.$, monomer $)$, and signals from $\mathrm{AAB}$, such as $m / z 59\left(\mathrm{C}_{3} \mathrm{H}_{9} \mathrm{~N}^{+}\right), m / z 77\left(\mathrm{C}_{6} \mathrm{H}_{5}{ }^{+}\right), m / z 92\left(\mathrm{C}_{6} \mathrm{H}_{6} \mathrm{~N}^{+}\right), m /$ $z 107\left(\mathrm{C}_{6} \mathrm{H}_{7} \mathrm{~N}_{2}{ }^{+}\right)$, and $m / z 198\left(\mathrm{C}_{12} \mathrm{H}_{12} \mathrm{~N}_{3}{ }^{+}\right.$, monomer) (Fig. 2).

The identified fragment ions originating from either HP $\beta C D$ or AAB (Fig. 2) appear at unique nominal $m / z$ values (Table 2). They can thus be used to obtain chemical maps of the distribution of $\mathrm{HP} \beta \mathrm{CD}$ and $\mathrm{AAB}$ on the fiber surfaces. Individual nanofibers in Mat I (HP $\beta C D-A A B=1: 0.3, \mathrm{HP} \beta C D 100 \mathrm{w} / \mathrm{v} \%)$ and Mat IV (HP $\beta C D-A A B=1: 1$ molar ratio, HP $\beta C D 130 \mathrm{w} / \mathrm{v} \%$ ) were imaged using the chemical contrasts observed (Fig. 3). The TOF-SIMS chemical mapping results show that the ICs were homogeneously distributed and randomly oriented without preferential allocation. The cavity-on-bead structure in Mat I is probably due to that the lower inner pressure compared to ambient spinning conditions has built up from the CD ICs system which has a lower water content in the CD cavities.

\section{Integrity of electrospun HPBCD-AAB-ICs}

The thermal characterizations of the HP $\beta C D-A A B-I C$ nanofibers were carried out by TGA and DSC techniques. The pure AAB and HP $\beta C D$ powders were also analyzed for comparison.

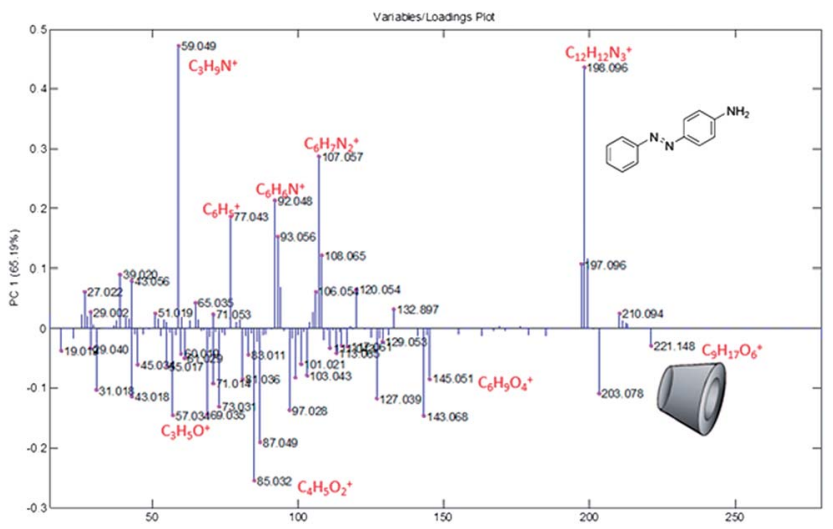

Fig. 2 Representative positive ion ToF-SIMS spectra recorded from Mat IV. Major peak assignments are shown in red.

Table 2 Peak assignments derived from the positive ion ToF-SIMS spectra in Fig. 2

\begin{tabular}{lllll}
\hline $\mathrm{HP} \beta C D(m / z)$ & 31 & 57 & 85 & 97 \\
& $\mathrm{CH}_{3} \mathrm{O}^{+}$ & $\mathrm{C}_{3} \mathrm{H}_{5} \mathrm{O}^{+}$ & $\mathrm{C}_{4} \mathrm{H}_{5} \mathrm{O}_{2}{ }^{+}$ & $\mathrm{C}_{5} \mathrm{H}_{5} \mathrm{O}_{2}{ }^{+}$ \\
AAB $(m / z)$ & 27 & 39 & 59 & 65 \\
& $\mathrm{C}_{2} \mathrm{H}_{3}{ }^{+}$ & $\mathrm{C}_{3} \mathrm{H}_{3}{ }^{+}$ & $\mathrm{C}_{3} \mathrm{H}_{9} \mathrm{~N}^{+}$ & $\mathrm{C}_{5} \mathrm{H}_{5}{ }^{+}$ \\
$\mathrm{HP} \beta C D(m / z)$ & 127 & 143 & 203 & 221 \\
& $\mathrm{C}_{6} \mathrm{H}_{7} \mathrm{O}_{3}{ }^{+}$ & $\mathrm{C}_{7} \mathrm{H}_{11} \mathrm{O}_{3}{ }^{+}$ & $\mathrm{C}_{10} \mathrm{H}_{19} \mathrm{O}_{4}{ }^{+}$ & $\mathrm{C}_{9} \mathrm{H}_{17} \mathrm{O}_{6}{ }^{+}$ \\
AAB $(m / z)$ & 77 & 92 & 107 & 198 \\
& $\mathrm{C}_{6} \mathrm{H}_{6}{ }^{+}$ & $\mathrm{C}_{6} \mathrm{H}_{6} \mathrm{~N}^{+}$ & $\mathrm{C}_{6} \mathrm{H}_{7} \mathrm{~N}_{2}{ }^{+}$ & $\mathrm{C}_{6} \mathrm{H}_{7} \mathrm{~N}_{2}{ }^{+}$
\end{tabular}
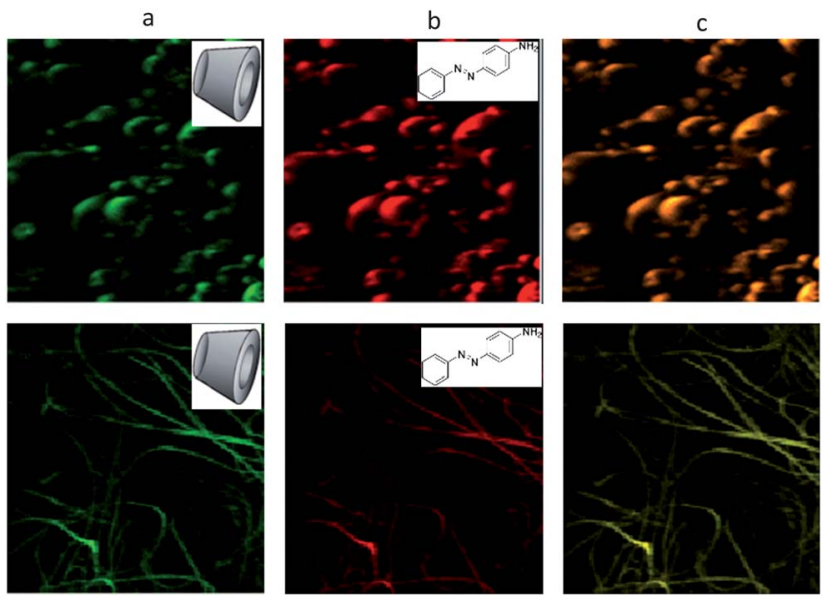

Fig. 3 ToF-SIMS chemical images of the HPBCD-AAB-IC Mats I (upper panel, area: $50 \mu \mathrm{m} \times 50 \mu \mathrm{m}$ ) and Mat IV (lower panel, area $500 \mu \mathrm{m} \times 500 \mu \mathrm{m}$ ). Column (a): HPßCD fragment ion images; column (b): $A A B$ fragment ion images; and column (c): overlay images of column (a) and column (b).

TGA thermograms of pure $\mathrm{AAB}, \mathrm{HP} \beta \mathrm{CD}$ nanofibers, and HP $\beta C D-A A B-I C$ fibers are depicted in Fig. 4a. The degradation of $\mathrm{AAB}$ started at about $122^{\circ} \mathrm{C}$, while the onset temperature for the HPBCD-AAB-IC Mat III was observed at $148{ }^{\circ} \mathrm{C}$. Thus, the thermal degradation temperature of $\mathrm{AAB}$ in ICs has shifted to a higher temperature when compared to that of pure AAB. From the TGA data, the $\mathrm{AAB}$ amount was calculated to be $6.07 \%$, which corresponds to a 1:0.7 molar ratio complexation between $\mathrm{HP} \beta \mathrm{CD}$ and $\mathrm{AAB}$, while the main weight loss $(84 \%)$ observed at $300{ }^{\circ} \mathrm{C}$ belongs to HPßCD.

DSC is a useful technique for determining whether the guest molecules are included inside the CD cavities, ${ }^{\mathbf{1 9}}$ since a thermal transition such as the melting point $\left(T_{\mathrm{m}}\right)$ of guest molecules would be observed if there were any free uncomplexed guest molecules present in the CD-IC system. The HP $\beta C D-A A B-I C$ Mat III were also characterized by the differential scanning calorimetry (DSC) technique C (Fig. 4b) in order to verify whether the $\mathrm{AAB}$ was included in the $\mathrm{CD}$ cavities or not. The DSC thermogram of pure AAB showing a melting point about $122{ }^{\circ} \mathrm{C}$ is also given for comparison. The DSC thermogram of HP $\beta C D-A A B-I C$ fibers did not show any melting peak for free $\mathrm{AAB}$, indicating complete inclusion complexation $\mathrm{AAB}$ with HP $\beta C D$. The absence of a thermal event such as $T_{\mathrm{m}}$ for the guest molecule AAB in HPßCD-AAB-IC fibers correlates with the TGA

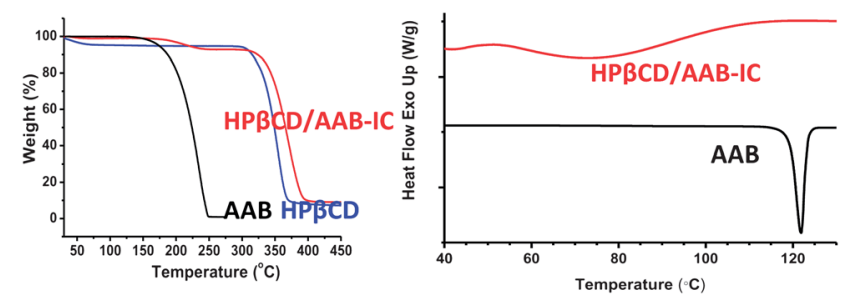

Fig. 4 (a) TGA spectra of the electrospun HPBCD-AAB-IC Mat III and the components $A A B$ and HPBCD, (b) DSC spectra of the electrospun HPBCD-AAB-IC Mat III and AAB. 
data (Fig. 4a), where the thermal degradation temperature of $\mathrm{AAB}$ in ICs shifted to a higher temperature.

Furthermore, as shown in FTIR spectra (Fig. S1 $\dagger$ ), characteristic peaks of AAB shifted from 1597 to $1602 \mathrm{~cm}^{-1}$ and from 1504 to $1508 \mathrm{~cm}^{-1}$ after forming ICs with HPßCD. HPßCD-AABIC fibers show no diffraction pattern for $\mathrm{AAB}$ in the XRD data (Fig. S2 $\dagger$ ). All these data support the findings of a true inclusion complexation in electrospun HPßCD-AAB-IC fibers, demonstrating the integrity of the ICs upon electrospinning.

\section{UV-response}

PRIOR TO ELECTROSPINNING. UV irradiation triggers the photoisomerization of $\mathrm{AAB}$ from the trans form to its cis form, and consequently the dissociation of the HPßCD-AAB-ICs. UV irradiation prior to electrospinning caused precipitation of $\mathrm{AAB}$ from the aqueous IC solution (Fig. S3 $\dagger$ ). The suspension could be switched back to the clear solution upon heating, indicating the re-association of the ICs. The switchability evaluation of ICs is, however, not applicable to the process of UV-electrospinning or the electrospun IC nanofibers.

UV-ELECTROSPINNING. Electrospinning under UV irradiation was further carried out. Significant increases of diameters and diameter distributions were observed, compared with electrospinning without UV irradiation (Table 3 and Fig. S4†). Because the self-assembly forces of the ICs consist of both hydrogen bondings between CDs and $\pi-\pi$ stacking between trans AABs, the photo-isomerization of AAB to the cis form, and the subsequent dissociation of ICs would cause disturbance to the selfassembled supramolecular structure and further interrupt the inherent molecular entanglement for the electrospinning process. Thus electrospinning became unstable and the resulting beads (Mat UV-I and Mat UV-II) or fibers (Mat UV-III) demonstrated broader diameter distributions. Meanwhile, as the increase of the viscosity of the solution would hinder molecular mobility for IC dissociation, the changes of diameter and diameter distribution decreased when HPßCD-AAB concentration increased (Table 3).

IN SITU AFM QUANTITATIVE NANOMECHANICAL MAPPING (POST ELECTROSPINNING). AFM based quantitative nanomechanical mapping (QNM) is a novel AFM derivative technique allowing for simultaneous recording of topographical and mechanical properties, thereby determining the nanoscale mechanical stiffness of the fibers and tip-sample interaction. ${ }^{21}$ The UV response of the electrospun IC nanofibers was further characterized by in situ imaging using this technique. The overview topography image of a single fiber from HP $\beta C D-A A B-I C$ Mat IV is depicted in Fig. 5A, where the inset square indicates the further zoom-in position where the QNM was performed to investigate the local nanoscale structure. As shown in Fig. 5B and E, before and after in situ UV exposure, respectively, no polymeric fibrillar structure $^{22}$ was observed in the zoom-in topography images. Meanwhile, the obtained uneven surface in Mat IV (Fig. 5B), which resulted from full stretching of those beads with cavities in Mat I (Fig. 1a), became smoother upon UV exposure (Fig. 5E), as summarized with the horizontal line profiles in Fig. 5D.

Furthermore, the tip-sample interaction force maps before and after in situ UV exposure, as shown in Fig. 5C and F, respectively, were recorded simultaneously. Under ambient condition of $44 \%$ humidity, a water layer was captured on the sample surface. Hence, the capillary phenomenon between the AFM tip and the sample appears each time when the tip interacts with the sample surface, which is reflected in the recorded values of the adhesion forces between the tip and the sample during the force mapping. ${ }^{23}$ According to the adhesion force distributions extracted from Fig. 5C and F, it is clear that after UV exposure the tip-sample interaction force decreased from $10.66 \pm 0.63 \mathrm{nN}$ to $5.91 \pm 0.42 \mathrm{nN}$. As known, trans azobenzene transformed to cis azobenzene upon UV exposure, which will be too bulky to remain inside the CD cavities and consequently needs to be released. While the resulting molecular movement changed the fiber surface topography, the hydrophobic nature of the released $\mathrm{AAB}$ also induced a decrease in the surface hydrophilicity. It is known that the less hydrophilic the sample is, the less water it is able to hold, and consequently the less adhesion force between the sample and the tip would occur. Therefore, the significant change in the topography and

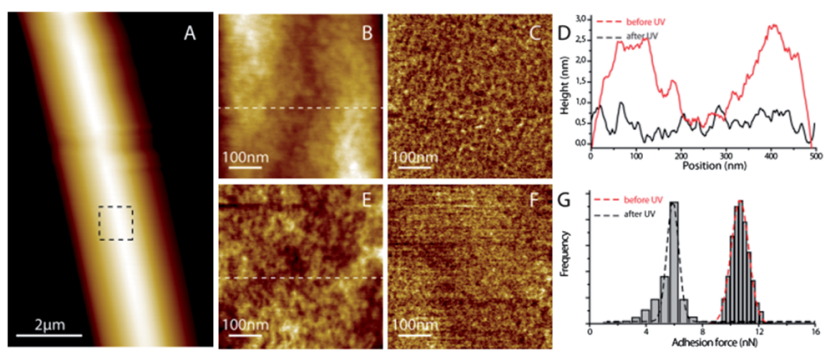

Fig. 5 AFM quantitative nanomechanical mapping of the HP $\beta C D-A A B-I C$ Mat IV before and after UV irradiation. (A): The overview of the fiber; the inset square indicates the position where AFM nanomechanical maps are recorded; ( $B$ and $E$ ): the topography images before and after UV exposure; (D): the horizontal line profiles across ( $B$ and $E$ ); ( $C$ and $F$ ): the corresponding tip-sample adhesion maps of ( $B$ and $E$ ) respectively; $(G)$ : the tip-sample adhesion force distribution before $(10.66 \pm 0.63 \mathrm{nN})$ and after UV exposure (5.91 $\pm 0.42 \mathrm{nN})$.

Table 3 Electrospinning of HPßCD-AAB-ICs under UV irradiation

\begin{tabular}{|c|c|c|c|c|c|}
\hline $\operatorname{Mat}^{a}$ & $\begin{array}{l}\mathrm{HP} \beta \mathrm{CD}-\mathrm{AAB} \\
\text { molar ratio }\end{array}$ & Fiber morphology & $\begin{array}{l}\text { Diameter }(\mu \mathrm{m}) \\
\text { without UV }\end{array}$ & Diameter $(\mu \mathrm{m})$ with UV & $\begin{array}{l}\text { Change in mean } \\
\text { diameter }(\%)\end{array}$ \\
\hline UV-I & $1: 0.15$ & Beads & $1.81 \pm 0.94$ & $4.04 \pm 1.78$ & 120.44 \\
\hline UV-II & $1: 0.3$ & Beads & $2.32 \pm 1.14$ & $3.99 \pm 2.48$ & 74.14 \\
\hline UV-III & $1: 0.7$ & Nano-microfibers & $0.94 \pm 0.23$ & $1.47 \pm 0.49$ & 55.32 \\
\hline
\end{tabular}

${ }^{a}$ UV-I: 100 w/v\% HPßCD, 2 w/v\% AAB; UV-II: 100w/v\% HPßCD, 4 w/v\% AAB; UV-III: 140 w/v\% HP $\%$ CD, 12 w/v\% AAB. 
adhesion force upon in situ UV exposure is solid proof of the UV response of the electrospun $\mathrm{HP} \beta \mathrm{CD}-\mathrm{AAB}-\mathrm{IC}$ fiber.

\section{Conclusions}

The present study is the first case where supramolecules with stimuli response were electrospun into nanofibers with retained activity. The integrity of electrospun HP $\beta C D-A A B-I C$ was proven by TGA, DSC, together with FTIR and XRD. The lower water content in the CD cavities builds up a lower inner pressure during electrospinning, which caused the cavity-on-bead structure at a low concentration of ICs. The homogeneous distribution of HP $\beta C D-A A B-I C$ was confirmed by surface chemistry mapping using ToF-SIMS.

The trans-cis isomerization of azobenzene triggered by UV light caused a significant change in the AAB molecular geometry and subsequently the dissociation from the ICs. The UV response of the ICs prior to, during and post electrospinning was investigated. UV irradiation prior to electrospinning caused precipitation of $\mathrm{AAB}$ from the aqueous IC solution. UV irradiation during electrospinning flight demonstrated interruption of the ICs and consequently broader diameter distributions were obtained. Post-spinning UV irradiation induced topography and adhesion force changes on the electrospun nanofiber surfaces, revealed by in situ AFM quantitative nanomechanical mapping.

Although the existence of CDs and their use in the pharmaceutical industry have been documented for decades, it is only recently that their exploration in applications beyond the solubilization and stabilization of small molecules has occurred. We believe the combination of the photo-responsibility from azobenzenes and the broad pharmaceutical applications of $\mathrm{CD}$ in a fibrous manner may flourish their potential in controlled drug delivery, sensors, and optical storage. Further study based on our previous study ${ }^{7 d}$ and CD prodrug in this direction is currently underway.

Furthermore, the present novel findings again proved the simplicity, robustness, and versatility of the electrospinning technique, extending its great potential in a broad range of research areas.

\section{Acknowledgements}

We gratefully acknowledge the Danish Council for Strategic Research for the funding to the ElectroMed Project at the iNANO Center, and the Lundbeck Foundation and the Carlsberg Foundation for their financial support. State Planning Organization (DPT) of Turkey is acknowledged for the support of the UNAM-Institute of Materials Science and Nanotechnology. Dr Uyar acknowledges Marie Curie International Reintegration Grant (IRG) NANOWEB (PIRG06-GA-2009-256428). We also thank A. Celebioglu and F. Kayaci for performing XRD, FTIR, DSC and TGA measurements.

\section{Notes and references}

1 H. Schlenk and D. M. Sand, J. Am. Chem. Soc., 1961, 83, 23122320.
2 (a) M. E. Davis and M. E. Brewster, Nat. Rev. Drug Discovery, 2004, 3, 1023-1035; (b) A. Kumari, S. K. Yadav and S. C. Yadav, Colloids Surf., B, 2010, 75, 1-18.

3 V. J. Stella, V. M. Rao, E. A. Zannou and V. Zia, Adv. Drug Delivery Rev., 1999, 36, 3-16.

4 (a) S. Y. Jeong and S. W. Kim, Arch. Pharmacal Res., 1986, 9, 63-73; (b) R. Langer and D. A. Tirrell, Nature, 2004, 428, 487-492; (c) M. A. C. Stuart, W. T. S. Huck, J. Genzer, M. Muller, C. Ober, M. Stamm, G. B. Sukhorukov, I. Szleifer, V. V. Tsukruk, M. Urban, F. Winnik, S. Zauscher, I. Luzinov and S. Minko, Nat. Mater., 2010, 9, 101-113; (d) M. Bikram, A. M. Gobin, R. E. Whitmire and J. L. West, J. Controlled Release, 2007, 123, 219-227.

5 F. Ercole, T. P. Davis and R. A. Evans, Polym. Chem., 2010, 1, 37-54.

6 G. S. Kumar and D. C. Neckers, Chem. Rev., 1989, 89, 19151925.

7 (a) P. Gorostiza and E. Y. Isacoff, Science, 2008, 322, 395-399; (b) Y. L. Yu, M. Nakano and T. Ikeda, Nature, 2003, 425, 145145; (c) R. Klajn, P. J. Wesson, K. J. M. Bishop and B. A. Grzybowski, Angew. Chem., Int. Ed., 2009, 48, 70357039; (d) M. Chen and F. Besenbacher, ACS Nano, 2011, 5, 1549-1555.

8 M. R. Banghart, M. Volgraf and D. Trauner, Biochemistry, 2006, 45, 15129-15141.

9 Y. Liu, Y. L. Zhao, Y. Chen and D. S. Guo, Org. Biomol. Chem., 2005, 3, 584-591.

10 (a) X. J. Liao, G. S. Chen, X. X. Liu, W. X. Chen, F. Chen and M. Jiang, Angew. Chem., Int. Ed., 2010, 49, 4409-4413; (b) K. Peng, I. Tomatsu and A. Kros, Chem. Commun., 2010, 46, 4094-4096; (c) B. Schierling, A. J. Noel, W. Wende, L. T. Hien, E. Volkov, E. Kubareva, T. Oretskaya, M. Kokkinidis, A. Rompp, B. Spengler and A. Pingoud, Proc. Natl. Acad. Sci. U. S. A., 2010, 107, 1361-1366; (d) W. Xiao, W. H. Chen, X. D. Xu, C. Li, L. Zhang, R. X. Zhuo and X. Z. Zhang, Adv. Mater., 2011, 23, 3526-3530; (e) G. D. Fu, L. Q. Xu, F. Yao, G. L. Li and E. T. Kang, ACS Appl. Mater. Interfaces, 2009, 1, 2424-2427.

11 (a) X. F. Lu, C. Wang and Y. Wei, Small, 2009, 5, 2349-2370; (b) M. L. Chen, M. D. Dong, R. Havelund, V. R. Regina, R. L. Meyer, F. Besenbacher and P. Kingshottt, Chem. Mater., 2010, 22, 4214-4221.

12 M. G. McKee, J. M. Layman, M. P. Cashion and T. E. Long, Science, 2006, 311, 353-355.

13 M. P. Cashion, X. L. Li, Y. Geng, M. T. Hunley and T. E. Long, Langmuir, 2010, 26, 678-683.

14 G. Singh, A. M. Bittner, S. Loscher, N. Malinowski and K. Kern, Adv. Mater., 2008, 20, 2332-2336.

15 X. Z. Yan, M. Zhou, J. Z. Chen, X. D. Chi, S. Y. Dong, M. M. Zhang, X. Ding, Y. H. Yu, S. Shao and F. H. Huang, Chem. Commun., 2011, 47, 7086-7088.

16 M. Bonini, S. Rossi, G. Karlsson, M. Almgren, P. Lo Nostro and P. Baglioni, Langmuir, 2006, 22, 1478-1484.

17 Y. F. He, P. Fu, X. H. Shen and H. C. Gao, Micron, 2008, 39, 495-516.

18 (a) A. Celebioglu and T. Uyar, Chem. Commun., 2010, 46, 69036905; (b) A. Celebioglu and T. Uyar, Nanoscale, 2012, 4, 621-631. 
19 A. Celebioglu and T. Uyar, Langmuir, 2011, 27, 6218-6226.

20 F. B. De Sousa, J. D. T. Guerreiro, M. L. Ma, D. G. Anderson, C. L. Drum, R. D. Sinisterra and R. Langer, J. Mater. Chem., 2010, 20, 9910-9917.

21 (a) M. Dong and O. Sahin, Nat. Commun., 2011, 2, 247; (b) M. D. Dong, S. Husale and O. Sahin, Nat. Nanotechnol., 2009, 4, 514-517; (c) I. Medalsy, U. Hensen and D. J. Muller, Angew. Chem., Int. Ed., 2011, 50, 12103-12108. 22 M. Chen, S. Gao, M. D. Dong, J. Song, C. Yang,
K. A. Howard, J. Kjems and F. Besenbacher, ACS Nano, 2012, 6, 4835-4844.

23 (a) M. Binggeli and C. M. Mate, Appl. Phys. Lett., 1994, 65, 415-417; (b) L. Xu, A. Lio, J. Hu, D. F. Ogletree and M. Salmeron, J. Phys. Chem. B, 1998, 102, 540-548; (c) R. D. Piner, J. Zhu, F. Xu, S. H. Hong and C. A. Mirkin, Science, 1999, 283, 661-663; (d) H. Zhao, S. Zhang, Q. Li, Y. Li, B. Liu, F. Besenbacher and M. Dong, RSC Adv., 2012, 2, 2732-2735. 